\title{
O Turista da Região Encontro das Águas: um estudo exploratório da demanda turística no Centro-Oeste Brasileiro
}

\author{
The tourist Encontro das Águas Region: an exploratory study on tourism demand \\ in Brazilian Midwest
}

\author{
Rita Maria de Paula Garcia (GARCIA, R. M. de P.)
}

RESUMO - O turismo é um fenômeno espacial que atinge diferentemente os lugares e as pessoas revelando práticas particulares. No Centro-Oeste brasileiro, mais precisamente no Rio Araguaia, o turismo se amplia na oferta de serviços e no crescimento da demanda, contudo são escassos os levantamentos estatísticos, logo, pouco se conhece do turismo e do turista que escolhe o interior do Brasil para realizar eventos, negócios ou praticar lazer. As investigações do processo de turistificação dos lugares, das relações sociais e da organização do espaço também são escassas. Na metodologia utilizou-se de pesquisa bibliográfica e aplicação de 95 formulários mensais ao longo de 12 meses, ou seja, 1.140 turistas respondentes no período de abril de 2012 a março de 2013. Os respondentes foram turistas que se destinavam aos Municípios de Aragarças no Estado de Goiás (GO), Pontal do Araguaia e Barra do Garças no Estado de Mato Grosso (MT), destinos indissociáveis pela proximidade de seus núcleos urbanos e pelas práticas espaciais do turismo. O objetivo da pesquisa consistiu em identificar o perfil do turista e suas motivações para o turismo na Região Encontro das Águas, e consequentemente revelar a espacialidade do turista. O turismo, nesta localidade, estava se produzindo amparando-se na natureza como principal atrativo e na motivação do encontro de familiares e amigos (30,1\%) no destino (VFR Travellers), além das motivações como: lazer $(26,7 \%)$, negócios $(19,1 \%)$, eventos $(7,3 \%)$ e outros $(16,8 \%)$.

Palavras-chave: Turismo; Centro-Oeste; Demanda turística; Espacialidade.

ABSTRACT - Tourism is a spatial phenomenon that affects differently the places and people revealing private practices. In Brazilian Midwest, more precisely in Araguaia River, the tourism enlarges in the service offer and in the demand growth however there are few statistical surveys, so little is known about tourism and the tourist who chooses the interior of Brazil to hold events, business or leisure practice. The process investigation of places touristification, social relations and the organization of space they are also weak. The methodology used is bibliographic research and it was applied 95 forms monthly over 12 months, in other words, 1,140 tourists answered from April 2012 to March 2013. The respondents were tourists whose destination were Aragarças in Goiás (GO), Pontal do Araguaia and Barra do Garças in Mato Grosso (MT), indissoluble destinations by their proximity to urban centers and by space practices of tourism. The research aim was to identify the profile of the tourist and their motivations

\footnotetext{
* Formação: Graduação em Turismo e Hotelaria pela Universidade Norte do Paraná (UNOPAR), Mestrado em Geografia pela Universidade Federal do Mato Grosso do Sul (UFMS) e Doutorado em Geografia pela Universidade Federal Fluminense (UFF). Atividade profissional: Docente do Curso de Turismo da Universidade do Estado de Mato Grosso (UNEMAT), Campus de Nova Xavantina. Endereço físico para correspondência: Avenida Professor Doutor Renato Figueiro Varella, s./n. CEP: 78690-000 Nova Xavantina - Mato Grosso (Brasil). E-mail: ritagarcia@unemat.br
} 
for tourism in these towns (Encontro das Águas Region), and thus reveal the spatiality of the tourist. The survey results showed that tourism in these places was produced being supported in nature as main attraction and the motivation of family and friends meeting (VFR Travellers) (30.1\%), in addition to other motivations as: leisure (26.7\%), business $(19.1 \%)$, events $(7.3 \%)$ and others $(16.8 \%)$.

Key words: Tourism; Brazilian Midwest; Tourism demand; Spatiality. 


\section{INTRODUÇÃO}

As relações socioespaciais estabelecidas na esfera global são amplamente difundidas e discutidas sobre o rótulo de globalização e que contraditória e complementarmente estão intimamente relacionadas ao local, às suas particularidades, onde é possível distinguir identidades e reconhecê-las como em constante mutação nunca estáticas e/ou enrijecidas.

Em um cenário de informações, ações fluídas e mobilidade, o turismo desencadeia inter-relações que superam a previsibilidade da vida cotidiana e insere novos agentes sociais com diferentes modos de vida e distintos objetivos a serem alcançados em determinado prazo, compartilhando do espaço da população de um local. $\mathrm{Na}$ vertente do mercado turístico, Nascimento et al. (2013, p. 405) afirmam que "a lógica do desenvolvimento da atividade turística justifica-se pela diferenciação do espaço (representado pelo produto turístico), que se acentua através do aumento da competitividade existente entre os destinos turísticos".

Várias áreas do conhecimento debruçam-se na reflexão sobre o turismo, denotando a relevância desse fenômeno, o qual necessita de aprofundamento teóricometodológico em um esforço de convergência da produção epistemológica, empírica e técnica para avanços mais profícuos.

Metodologias e critérios são lançados para analisar a espacialidade do turismo. Mas em que consiste tal espacialidade? $\mathrm{O}$ uso comum e a empregabilidade rotineira das palavras "espaço" e "tempo" no cotidiano das pessoas oferece a diversas áreas do conhecimento um convite a reflexões constantes, a fim de explicar as nuances pelas quais o espaço e o tempo (ou espaço-tempo) são condicionados e condicionantes pela/da sociedade. $\mathrm{O}$ espaço o qual é tratado aqui é o espaço geográfico, revestido e permeado pela temporalidade, então espacialidade. O cenário atual, que compreende mudanças e ações de proporções globais; geração de informação aliada à telemática; alternativas de deslocamento e transporte de pessoas e de mercadorias; segurança e confiabilidade depositadas em profissionais e empresas com matrizes em locais distintos (GARCIA, 2012), enfim, tudo isso não faz parte da proposta deste estudo, mas sua relevância não deixa de ser reconhecida para fins de contextualização da prática do turismo em um panorama mais amplo. 
Como o turismo é exequível a partir da decisão das pessoas em viajar, estas, enquanto agentes de análise, tornam-se importantes objetos de pesquisa para a compreensão não só da atividade, como também da própria sociedade e de sua capacidade de produzir o espaço, pelos diversos e até contraditórios significados atribuídos a acidentes geográficos, a formas simbólicas ${ }^{1}$ e a manifestações culturais.

A denominação "turista" é a expressão do sujeito-objeto social do turismo, capaz de aglutinar indivíduos (de diferentes classes, etnias, ideologias, raças e crenças) os quais têm em comum o deslocamento e a permanência temporária em lugares diferentes de sua residência permanente. Não obstante, esse termo, mesmo no singular, vem a representar uma coletividade que desencadeia usos e apropriações de um espaço. $\mathrm{O}$ turista é o agente preponderante (mola propulsora) e, inquestionavelmente, seu movimento incide sobre os demais agentes, são eles: o Estado, o mercado, os trabalhadores, os promotores territoriais, a comunidade local etc. Em cada destino turístico (consolidado ou não), há uma variação na intensidade dos agentes atuantes, os quais são dependentes do contexto socioespacial e das relações estabelecidas na história de uma dada sociedade, bem como de suas relações de produção e de reprodução capitalista.

Ao encontro e atentos à "ebulição da diversidade de experiências e reconstruções do espaço", apontada por Haesbaert (2010), a apreensão do turismo na Região Encontro das Águas - Centro-Oeste do Brasil - despertou motivação para pesquisar a identificação e a descrição do turista e, por consequência, do fenômeno turístico.

A Região Encontro das Águas é uma denominação que remete à confluência dos rios Araguaia e das Garças e também ao aglomerado urbano de três municípios: Aragarças (GO), Pontal do Araguaia (MT) e Barra do Garças (MT).

\footnotetext{
${ }^{1}$ CORRÊA, R. L. Formas simbólicas e espaço: algumas considerações. Trabalho apresentado na aula inaugural do Programa de Pós-graduação em Geografia da UFF. Niterói: UFF, 2007.
} 


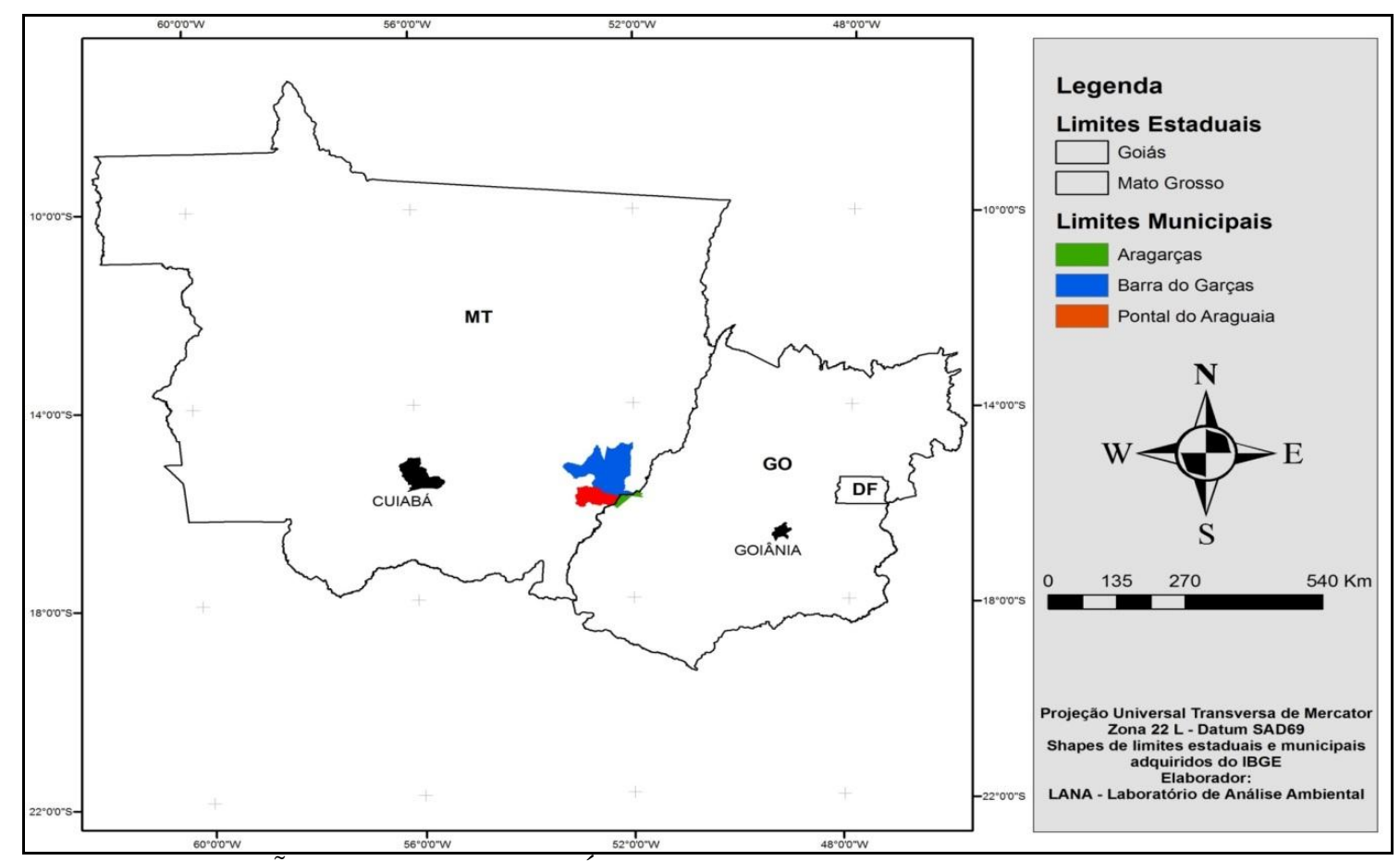

FIGURA 1 - REGIÃO ENCONTRO DAS ÁGUAS.

FONTE: Universidade do Estado de Mato Grosso (2013a).

A Região está no domínio do bioma Cerrado, onde se localizam praias fluviais do rio Araguaia e afluentes que formam o Pantanal do Araguaia (MARIMON et al., 2008). Tal Região tem uma fitogeografia particular aliada à geomorfologia, que se destaca na Serra Azul, na Serra do Roncador, nos paredões, nas cachoeiras, nos canyons e nos vales. As manifestações culturais correspondem ao artesanato indígena, a festas populares, aos acontecimentos de cunho místico ou provenientes da população indígena (mais especificamente, das etnias xavante e bororo) (NASCIMENTO, 2011). Nesse sentido, delineia-se o objetivo do artigo apresentado: identificar as características do turista, suas motivações e a espacialidade do turismo na Região Encontro das Águas. Dessa forma, o artigo está estruturado em revisão bibliográfica, procedimentos metodológicos, resultados, discussões e considerações finais. 


\section{BREVE ASPECTO TEÓRICO-METODOLÓGICO DO TURISMO: RUMO À ESPACIALIDADE DO TURISMO}

Para a Organização Mundial do Turismo² (apud OMT, 2001, p. 3), “o turismo compreende as atividades realizadas pelas pessoas durante suas viagens e estadas em lugares diferentes do seu entorno habitual, por um período consecutivo inferior a um ano, por lazer, negócios ou outros". Por sua vez, o principal recurso utilizado para identificar o turista enquanto objeto está nos motivos da viagem, mas a definição de turista é abrangente, evasiva, suscita dúvidas e livre interpretação para inúmeras outras variáveis, principalmente no que tange à sua aplicabilidade. As dimensões sociais e/ou operacionais fundamentais para o entendimento da atividade não são mencionadas. $\mathrm{O}$ órgão afirma que o sistema turístico é o método mais eficiente para compreender as inter-relações de diferentes fatores que influem na dinâmica do turismo, tais como: demanda (formada por um conjunto de consumidores - ou possíveis consumidores - de bens e serviços turísticos), oferta (composta pelo conjunto de produtos, serviços e organizações envolvidas na atividade turística), espaço geográfico (base física na qual tem lugar a conjunção ou o encontro entre a oferta e a demanda e em que se situa a população residente), operadores de mercado (empresas e organismos cuja principal função é facilitar a inter-relação entre a oferta e a demanda, como agências de viagens, companhias de transporte regular, órgãos públicos e privados). (OMT, 2001).

No Brasil, o Ministério do Turismo, em consonância com a OMT e outros países, adota o método sistêmico (Sistema de Turismo) para demonstrar a operacionalização do turismo e realizarem pesquisas para estruturar suas ações. Além disso, também objetiva: executar a política nacional para o setor - promoção interna; zelar pela qualidade da prestação do serviço turístico brasileiro; formular planos, programas e ações destinados ao fortalecimento do turismo nacional e ainda promover o desenvolvimento da infraestrutura e a melhoria da qualidade dos serviços prestados (GARCIA, 2014). Em paralelo, o Instituto Brasileiro de Turismo (Embratur) concentrase na promoção, no marketing e no apoio à comercialização dos produtos, serviços e destinos turísticos brasileiros no exterior (BRASIL, 2013a). O entendimento de turismo

\footnotetext{
${ }^{2}$ ORGANIZACION MUNDIAL DEL TURISMO. Compendio de estadística del turismo 1988-1992. 14. ed. Madrid: s./ed., 1994.
} 
pelo Ministério do Turismo baseia-se teoricamente em duas vertentes: a econômica e a sociológica.

1. É uma atividade econômica representada pelo conjunto de transações compra e venda de serviços turísticos efetuadas entre os agentes econômicos do turismo. É gerado pelo deslocamento voluntário e temporário de pessoas para fora dos limites da área ou região em que têm residência fixa, por qualquer motivo, excetuando-se o de exercer alguma atividade remunerada no local que visita (EMBRATUR, 1992). 2. Conjunto de relações e fenômenos produzidos pelo deslocamento e permanência de pessoas fora do lugar de domicílio, desde que tais deslocamentos e permanência não estejam motivados por uma atividade lucrativa. (BRASIL, 2013a, p. 1).

Certamente, uma das faces do turismo é a econômica, a qual reflete diretamente nas pesquisas, pois é nessa vertente que são realizadas a maioria das pesquisas em turismo: embarques e desembarques internacionais e domésticos, receita cambial, receita cambial do turismo internacional no mundo, geração de emprego, cadastro de empreendimentos e serviços turísticos, entre outros, protagonizados por consumidores de vários países, culturas, motivações e poder aquisitivo.

$\mathrm{A} \mathrm{OMT}^{3}$ descreve o visitante como a pessoa que visita um país ou região que não seja de sua residência, por qualquer motivo, e que não venha a exercer, em tal local, ocupação remunerada (BENI, 2001). Esta definição inclui:

[...] turistas - visitantes temporários que permaneçam pelo menos vinte e quatro horas no país visitado, cuja finalidade de viagem pode ser classificada sob um dos seguintes tópicos: lazer (recreação, férias, saúde, estudo, religião e esporte), negócios, família, missões e conferências.

excursionistas - visitantes temporários que permaneçam menos de vinte e quatro horas no país visitado (incluindo viajantes de cruzeiros marítimos). (BENI, 2001, p. 35).

O turismo não é um fenômeno atrelado somente ao tempo livre e ao tempo de lazer, pois outras motivações também são incorporadas. Os indivíduos se deslocam e permanecem em localidades diferentes da sua residência habitual por motivos diversos, os quais incluem negócios, estudos ou saúde, e utilizam direta ou indiretamente os serviços turísticos, relacionando-se com a comunidade de um local e compartilhando ou construindo, por meio da experiência, suas representações na/da localidade.

\footnotetext{
${ }^{3}$ Em 1963 as Nações Unidas patrocinaram uma Conferência sobre Viagens Internacionais para fins de estatísticas internacionais e concluiu o que seria o visitante e em 1968 a Organização Mundial de Turismo (que então se chamava União Internacional de Organizações Oficiais de Viagens) aprovou essa definição (BENI, 2001).
} 
A prática social do turismo perpassa critérios mensuráveis e adentra na contemporaneidade, na subjetividade da experiência e das representações que são permeadas por agentes como o mercado, o Estado e a comunidade local.

O turismo produz espaço pela proeminência, periodicidade e frequência de fluxos por meio dos transportes e vias (aérea, hidroviária, marítima, ferroviária, rodoviária) e também pelo deslocamento articulado (pessoas, informações, mercadorias), que indicam a intensidade dos fluxos e das correntes de turistas e insumos (PEARCE, 2003). O espaço, como lugar de produção ou como produto e produção, é sempre um processo que se torna conteúdo propulsionado pelos seguintes agentes: o Estado, o mercado, os trabalhadores, os promotores territoriais, a comunidade local, o turista etc.

\section{PROCEDIMENTOS METODOLÓGICOS}

A Região Encontro das Águas compreende os municípios de Barra do Garças (MT), Pontal do Araguaia (MT) e Aragarças (GO), que possuem processo de formação motivado pelo garimpo e por estratégias de ocupação do Brasil Central (BORGES, 1987). O município de Barra do Garças possui uma extensão territorial de 9.078,983 km² (IBGE, 2013) e recebeu a primeira denominação de Barra Cuiabana, devido a uma pedra localizada na foz do Rio das Garças que servia de referência aos militares (BORGES, 1987). Pontal do Araguaia recebeu esse nome por situar-se em um pontal entre os rios Araguaia e das Garças, sua extensão territorial é de 2.738,777 km² (IBGE, 2013). Já o nome Aragarças resulta da junção dos nomes dos rios e substitui a denominação Barra Goiana; a extensão territorial de Aragarças é de 662,901 km². (IBGE, 2013).

O foco do fenômeno turístico investigado nesta pesquisa foi o sujeito turista; o universo de análise foram os turistas dos municípios de Barra do Garças (MT), Pontal do Araguaia (MT) e Aragarças (GO). No ano de 2006, os três municípios passaram a integrar a microrregião turística denominada Encontro das Águas, criada pelo Conselho Municipal de Turismo (COMTUR) de Barra do Garças e também por representantes dos demais municípios envolvidos (BARRA DO GARÇAS, 2001). O Conselho 
Municipal de Turismo "COMTUR" de Barra do Garças é um órgão normativo, deliberativo e de assessoramento (BARRA DO GARÇAS, 2001). Criado pela Lei $\mathrm{n}^{\circ}$ 2.357 de 15 de outubro de 2001, tal órgão tem como finalidade específica promover o turismo como fator de desenvolvimento social, econômico e cultural. (BARRA DO GARÇAS, 2001) $)^{4}$

A área correspondente aos municípios envolvidos na pesquisa caracterizando-se pelo predomínio do bioma cerrado e também pela presença de inúmeras nascentes (AQUINO; LATRUBESSE; SOUZA FILHO, 2008). A confluência de corpos d'água mais densos (rios) juntamente às águas termais atraem turistas para apreciar essas diversas possibilidades de "contato" com a água, ora coadjuvante ora protagonista da motivação para o turismo (GARCIA, 2014). Na pesquisa realizada - como será constatado posteriormente - destacou-se a relevância desse elemento na experiência turística.

O corpus empírico está caracterizado como estrutura aberta, ou seja, sem amostra operacional ${ }^{5}$. Pires (2010, p. 166) afirma que: “[...] toda pesquisa empírica tem um universo de análise, mas que nem toda pesquisa empírica retira uma amostra operacional. [...]”. Concordando com Deslauriers e Kérisit (2010), na pesquisa quantitativa, há a tendência em valorizar mais as regras técnicas de amostragem em detrimento da adequação ao objeto de pesquisa.

O desenvolvimento do turismo, ou de qualquer atividade, exige dados para reduzir os riscos de investimentos, para atender com maior precisão às necessidades dos turistas, entre outros. A escassez de dados também justifica esta pesquisa de campo. A identificação - tanto do turista, quanto das motivações da viagem e dos atrativos turísticos - indicados como relevantes - foi realizada por meio de pesquisa quantitativa, com aplicação de 95 formulários mensais, ao longo de 12 meses, ou seja, ao todo, foram 1.140 turistas respondentes no período compreendido entre abril de 2012 a março de 2013. A amostragem ficou caracterizada como não probabilística, pois a população total era desconhecida e variável durante o ato do levantamento. De acordo com Dencker

\footnotetext{
${ }^{4}$ BARRA DO GARÇAS. Conselho Municipal de Turismo. Lei $\mathbf{n}^{\mathbf{0}} 2.357$ de 15 de outubro de 2001. Dispõe sobre a criação do COMTUR. Barra do Garças, 15 out. 2001.

${ }^{5}$ Segundo Pires (2010), para extrair a amostra operacional, é necessário um universo de análise bem definido. O universo de análise se define como o "conjunto de todas as unidades empíricas que o pesquisador estabelece como a base de sua pesquisa e da qual ele retira uma amostra". (ROSE apud PIRES, 2010, p. 166).
} 
(1998, p. 214): "Entende-se por amostragem não probabilística qualquer tipo de amostragem em que a possibilidade de escolher determinado elemento do universo é desconhecida.".

Outro aspecto a ser levado em conta é que as vias de acesso e os meios de transporte disponíveis representam um fator determinante para a prática do turismo. No Brasil, as estimativas de fluxos de turistas são definidas a partir de embarques e desembarques em aeroportos e em algumas rodoviárias (predominantemente em capitais) (BRASIL, 2012b). No entanto, na Região Encontro das Águas, não havia aeroportos que estivessem atuando com voos regulares; os mais próximos eram: o Aeroporto Santa Genoveva em Goiânia (a 374 quilômetros) e o Aeroporto Internacional Marechal Rondon, em Várzea Grande, região metropolitana de Cuiabá (a 511 quilômetros). (VIAGEM E TURISMO, 2016).

O acesso rodoviário estava sendo o único disponível, por meio das rodovias federais: BR 158 e BR 070, e rodovias estaduais: MT 100 e GO 194 - essas duas últimas, inclusive, encontravam-se sem pavimentação no período de coleta de dados. Os meios de transporte eram os carros de passeio, utilitários leves, veículos de carga, motocicletas, vans, ônibus e micro-ônibus. Nesta pesquisa, não foram abordados condutores de veículos de carga, por entender-se que isso comprometeria a segurança dos condutores e da equipe nas rodovias, que nem sempre possuíam acostamentos. Além disso, tal ação reduziria a agilidade no processo de abordagem e liberação dos veículos. Da mesma forma, optou-se por abordar veículos em um único sentido, isto é, aqueles que chegavam à localidade. Essa decisão também foi tomada em função da manutenção da segurança da equipe de pesquisadores, formada por acadêmicos do Curso de Turismo da Universidade do Estado de Mato Grosso (UNEMAT) e por um professor.

Para identificar as motivações e os perfis dos turistas da região, optou-se por abordar aqueles que chegavam e partiam (em especial, passageiros nas rodoviárias) pelas principais vias de acesso à Região Encontro das Águas (Barra do Garças, Pontal do Araguaia e Aragarças) (apontados na FIGURA 2 abaixo), ou seja, as BR's: 070 acesso à cidade de Aragarças (5); 070 - acesso à cidade de Barra do Garças (2); 158 acesso à cidade de Barra do Garças (1); além da Rodoviária de Barra do Garças (3) e da Rodoviária de Aragarças (4). Para tanto, contou-se com o apoio da $8^{\text {a }}$ Delegacia de 
Polícia Rodoviária Federal de Barra do Garças, da $4^{\mathrm{a}}$ Companhia Independente da Polícia Militar de Aragarças e do $2^{\circ}$ Batalhão da Polícia Militar do Estado de Mato Grosso de Barra do Garças. Os policiais da Delegacia, da Companhia e do Batalhão nominados realizavam a abordagem dos condutores dos veículos que chegavam à localidade pelas rodovias citadas e, a seguir, a equipe aplicava os formulários junto aos viajantes voluntários. A MT 100, que dava acesso à Pontal do Araguaia e a Barra do Garças, e a GO 194, que dava acesso à Aragarças, possuíam baixo fluxo de veículos por não serem rodovias pavimentadas no período da coleta de dados. Assim, eliminaram-se esses acessos para ponto de coleta.

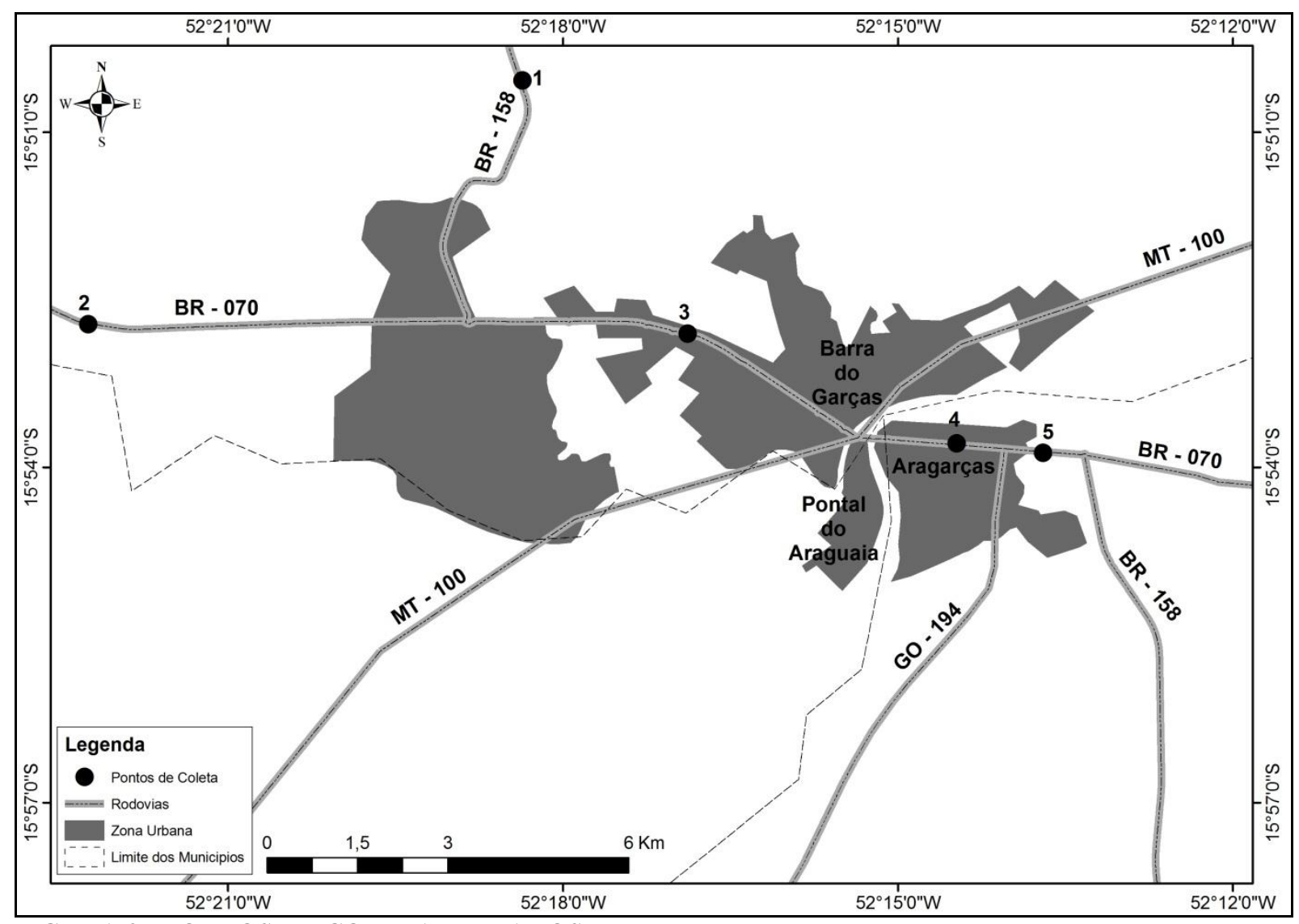

FIGURA 2 - PONTOS DE COLETA DE DADOS.

FONTE: Universidade do Estado de Mato Grosso (2013b).

Estabeleceu-se como critério que nem todos os voluntários poderiam responder ao formulário, pois deveriam ser caracterizados como turistas antes mesmo da aplicação. Para isso algumas questões foram feitas com base na aplicabilidade da classificação do que seria visitante - aplicabilidade esta definida pela Organização Mundial do Turismo em 2001 como: viagem com período consecutivo inferior a um 
ano, por lazer, negócios ou outros. Assim se identificou o "ser turista" no momento da coleta de dados.

Os respondentes da pesquisa teriam que ter idade acima de 12 anos, uma vez que, a partir dessa idade, segundo o Estatuto da Criança e do Adolescente, Lei $\mathrm{n}^{\circ}$ 8.069/90, artigo 83 (BRASIL, 1990), é possível viajar em transporte coletivo dentro do país sem a companhia dos pais ou responsáveis.

Nas rodoviárias, a abordagem foi realizada pela própria equipe e aplicada também junto aos voluntários que embarcavam ou desembarcavam em ônibus ou microônibus dos terminais rodoviários dos Municípios de Barra do Garças e Aragarças. É conveniente mencionar que o Município de Pontal do Araguaia não possuía terminal rodoviário.

A técnica consistiu na aplicação de um formulário composto por nove perguntas abertas, oito perguntas semiabertas e quatro perguntas fechadas, das quais apenas uma era encadeada.

Apesar de a pesquisa para elaboração do Plano de Desenvolvimento Integrado do Turismo Sustentável (PDITS - Polo Araguaia Mato-Grossense) não ter abrangido o município de Aragarças (GO), constatou-se que a projeção do fluxo de turistas para o Polo Araguaia no ano de 2012 foi de 39.724 turistas (MATO GROSSO, 2013). A projeção do turismo realizada pela Fundação Getúlio Vargas (FGV) foi baseada nas características do produto oferecido, na demanda vigente e nos estudos sobre o desenvolvimento do turismo no Brasil. (MATO GROSSO, 2013)

Segundo Tagliacarne (1976), para uma população de 50.000 pessoas e margem de erro desejada de 3\%, é necessária a aplicação de 1.087 formulários. Dessa forma, verifica-se que a amostra coletada de 1.140 turistas na Região Encontro das Águas atingiu o cálculo e a margem de erro estabelecidos. Na sequência, seguem os resultados da pesquisa de campo realizada no período de abril de 2012 a março de 2013, na Região Encontro das Águas. 


\section{A ESPACIALIDADE DO TURISTA DA "REGIÃO ENCONTRO DAS ÁGUAS"}

No turismo, as posições e as configurações dos atrativos turísticos são fundamentais e estão na gênese da prática da atividade, assim como atuam na experiência turística. Tal experiência é tanto resultado daquilo que o turista encontrará quanto da possibilidade de confluência de outras trajetórias, revelando múltiplas escalas da prática social por diferentes agentes.

Nesse sentido, considera-se que os resultados da investigação empírica sobre o perfil do turista da Região Encontro das Águas, sua origem, motivações e tempo de permanência poderiam contribuir significativamente para explicar tal afirmativa.

Dentre os resultados, tem-se que 38,8\% dos respondentes foram mulheres e $61,2 \%$ homens. Quanto à escolaridade dos turistas, 12,4\% possuía ensino fundamental incompleto; $6,8 \%$ ensino fundamental completo; $7,2 \%$ ensino médio incompleto; $31,8 \%$ dos respondentes possuíam ensino médio completo; 11,3\% superior incompleto; $19,0 \%$ superior completo; $8,8 \%$ possuía pós-graduação e 2,7\% não tinham educação formal.

A relação entre gênero e escolaridade permitiu afirmar que a escolaridade de maior expressividade no contexto geral dos respondentes foi o Ensino Médio Completo $(33,3 \%)$, sendo a maior representatividade para os homens nos níveis escolares de fundamental completo, médio completo e superior completo, respectivamente $7,2 \%$, $33,3 \%$ e 20,3\%. Já as mulheres representaram $6,1 \%, 29,5 \%$ e $17,0 \%$. Verificou-se existir uma maior quantidade de homens, em comparação com as mulheres, com escolaridade superior. Porém, que elas estudaram por mais tempo, dedicando-se à pósgraduação.

No que tange à faixa etária, os turistas respondentes da pesquisa tinham idade acima de 12 anos, como já explicado anteriormente. Dessa forma, 3,7\% dos respondentes tinham entre 12 e 17 anos; $15,2 \%$ entre 18 e 24 anos; $17,9 \%$ entre 25 e 31 anos; $22,5 \%$ entre 32 e 40 anos; 20,8\% entre 41 e 50 anos; $11,5 \%$ entre 51 e 59 anos e $8,4 \%$ dos respondentes estavam na faixa acima dos 60 anos.

Para tornar os dados mais visualizáveis, calculou-se separadamente o rendimento per capita do turista da Região Encontro das Águas por ano (2012-2013) em salários mínimos. Em seguida, tais dados foram agrupados e se chegou, assim, à seguinte tabela: 


\begin{tabular}{lcc}
\hline & $\mathrm{N}^{\circ}$ ABSOLUTO & $\mathrm{N}^{\circ}$ RELATIVO \\
\hline Até 1 SM & 326 & $28,6 \%$ \\
Mais de 1 SM até 2 SM & 324 & $28,4 \%$ \\
Mais de 2 SM até 3 SM & 147 & $12,9 \%$ \\
Mais de 3 SM até 5 SM & 170 & $14,9 \%$ \\
Mais de 5 a 10 SM & 89 & $7,8 \%$ \\
Mais de 10 a 20 SM & 29 & $2,5 \%$ \\
Mais de 20 SM & 10 & $0,9 \%$ \\
Sem renda & 1 & $0,1 \%$ \\
Não respondeu & 44 & $3,9 \%$ \\
\hline Total & 1140 & $100 \%$ \\
\hline
\end{tabular}

FONTE: Pesquisa de campo, 2013.

A renda média domiciliar per capita dos brasileiros correspondia a 2,5 salários mínimos (BRASIL, 2011), enquanto que a renda média dos $\operatorname{turistas}^{6}$ correspondeu a R $\$$ 2.062,26 durante a realização da pesquisa, nos anos de 2012/2013. O cálculo do rendimento médio domiciliar per capita do turista sob o salário mínimo de 2012 corresponderia a 3,3 salários mínimos e sob o salário mínimo de 2013 corresponderia a 3,0 salários mínimos. Embora não tenha havido uma correspondência precisa entre os dados, devido à alteração do salário mínimo durante a coleta de dados, concluiu-se que o turista apresentava rendimento superior à média do rendimento domiciliar per capita do brasileiro. Mais da metade dos turistas tinham rendimento domiciliar per capita de até 2 salários mínimos.

Os meios de deslocamento foram apresentados pelo número total de meios de transportes utilizados pelos turistas (1.152), sendo eles: avião e ônibus de linha regular (2 tipos de transporte) ou carro próprio (1 tipo de transporte). Os aeroportos utilizados pelos turistas, como mencionado, estavam localizados a uma distância de até 511 quilômetros e, por isso, foi necessário o uso de um segundo meio de transporte.

A predominância de transporte terrestre e, principalmente, veículo próprio $(48,8 \%)$ onerava a viagem, segundo Bonelli (2009) isso se deve aos gastos com manutenção do veículo e preço elevado do combustível.

As viagens, em sua maioria, aconteceram individualizadas (40,5\%). Estas foram movidas, sobretudo por visitas a amigos e parentes ou por negócios. As viagens em família $(33,8 \%)$ apresentaram como principais motivações o lazer e a visita a amigos e

\footnotetext{
${ }^{6}$ Considerou-se como renda domiciliar per capita a soma dos rendimentos mensais dos turistas de um domicílio dividida pelo número de seus moradores.
} 
parentes. $67,0 \%$ dos turistas afirmaram desconhecer o número de vezes que já haviam estado na Região Encontro das Águas.

Outro aspecto fundamental ao turismo é identificar a origem do turista. Segundo Motta, Ortiz e Ferraz (2001), a partir desse e de outros dados, pode-se calcular os custos de uma viagem e relacioná-los (junto com outros fatores) a uma frequência de visitas, de modo que uma relação de demanda seja estabelecida. O Brasil possui 27 unidades federativas, sendo 26 Estados e 1 Distrito Federal, dos quais se identificaram turistas provenientes de 20 Unidades Federativas, sendo 19 Estados (Acre, Alagoas, Bahia, Ceará, Espírito Santo, Goiás, Maranhão, Mato Grosso, Mato Grosso do Sul, Minas Gerais, Pará, Paraná, Pernambuco, Rio de Janeiro, Rio Grande do Sul, Rondônia, Santa Catarina, São Paulo e Tocantins) e do Distrito Federal. Encontraram-se ainda turistas provenientes de três países distintos: Argentina, Portugal e Espanha, porém, os turistas dos dois últimos países não eram, de fato, estrangeiros, mas sim brasileiros com residência no exterior.

O principal Estado emissor de turistas foi Mato Grosso (50,4\%), no entanto, o principal município emissor foi Goiânia (GO), que deteve $13,1 \%$ dos turistas respondentes, seguido de Cuiabá (MT), com 9,4\% e de Nova Xavantina (MT), com $6,4 \%$. Esses números revelaram que o turismo era, principalmente, regional, com viagens rodoviárias de até 511 quilômetros - distância entre Cuiabá e a Região Encontro das Águas.

Os motivos para as viagens foram variados: $30,1 \%$ dos respondentes apontaram a visita a amigos e a familiares; 26,7\%, o lazer; 19,1\%, negócios; 7,3\%, eventos e $16,8 \%$, outras razões (estudos, motivos profissionais, saúde, repouso, providenciar documentação, finanças, religião, compras, acompanhar amigo, concurso entre outras).

Por meio da pesquisa, foi possível identificar a motivação da viagem por procedência, permitindo caracterizar as demandas de cada estado e município na Região. A principal motivação para a viagem de turistas procedentes do Estado de Mato Grosso e do Distrito Federal foi visitar amigos e parentes (que correspondeu respectivamente a $30,0 \%$ e $50,0 \%$ dos respondentes). $32,9 \%$ dos turistas do Estado de Goiás mencionaram o lazer como principal motivação da viagem. Negócios, foi a principal motivação de mineiros $(42,3 \%)$, paulistas $(30,2 \%)$ e de pessoas provenientes 
de outros estados (Espírito Santo, Mato Grosso do Sul, Pará, Paraná, Rio Grande do Sul, Rondônia e Santa Catarina) (32,7\%).

De acordo com Backer" (apud BACKER, 2008, p. 60, tradução livre): "Viagem VFR é uma forma de viagem, envolvendo uma visita em que qualquer um (ou ambos), o objetivo da viagem ou o tipo de acomodação, envolve visitar amigos e/ou parentes". Esse tipo de viagem é menos suscetível, em relação a outras formas de turismo, aos fatores de sazonalidade (BACKER, 2009). Visiting Friends and Relatives ou Visitar Amigos e Parentes envolve a motivação e/ou o tipo de hospedagem no destino turístico, ou seja, o turista pode se deslocar para visitar parentes e amigos e/ou se hospedar na residência de parentes e amigos.

Os resultados da pesquisa apontaram que os adeptos ao lazer na Região Encontro das Águas revelaram-se mais representativos nos meses de junho (3,2\%), julho $(5,0 \%)$ e outubro $(4,1 \%)$, período que corresponde às férias escolares, a feriados nacionais (junho: Corpus Christi; e, outubro: Nossa Senhora Aparecida) e à Temporada de Praia nos municípios banhados pela Bacia Tocantins-Araguaia. Os principais atrativos destacados nesses meses foram: praias fluviais, Parque Estadual da Serra Azul (PESA) e bares e restaurantes.

Considera-se importante mencionar que as porções leste do Estado de Mato Grosso e oeste do Estado de Goiás são marcadas por duas estações anuais: uma chuvosa - com elevação dos níveis dos rios (outubro a março) e uma de estiagem - com redução dos níveis dos rios e surgimento de praias fluviais às margens do Rio Araguaia e de alguns afluentes também (abril a setembro) (GARCIA, 2014). Isto ocorre pelo excesso de sedimentos nos rios e pela pouca variação de altitude (Planície do Araguaia). (MARIMON et al, 2008)

No período de estiagem, principalmente entre os meses de junho e julho, acontecia, em vários municípios, o "Festival de Praia" - evento organizado por gestores públicos em que havia apresentações musicais, comercialização de alimentos e artesanatos, atividades recreativas e sócio-educativas, com alta demanda por serviços de

\footnotetext{
${ }^{7}$ BACKER, E. VFR tourism - the forgotten tourism phenomenon. In: RICHINS, H. (Ed.). Issues and developments in tourism futures. Proceedings from the Second National Conference on Tourism Futures - Sustainable Growth, Strategic Alliances and Positive Futures in Challenging Times 2003, p. 112.
} 
hospedagem, alimentação e transporte, devido ao aumento do número de turistas. (MATO GROSSO, 2013)

O “Turismo de negócios é o conjunto de atividades que resultam em viagens sob a responsabilidade de uma pessoa jurídica - empresa, órgão público, entidade de classe ou ONG - que absorve todas as despesas previstas em sua política de viagem [...]" (WADA, 2009, p. 215). Tal tipo de deslocamento envolve viagens corporativas, eventos empresariais e viagens de incentivos. (WADA, 2009)

Segundo dados da pesquisa, a principal motivação da viagem no início do ano era para negócio, com maior incidência em fevereiro $(3,2 \%)$ e março $(2,8 \%)$. Os eventos também assumiram relevância nas viagens, sobretudo nos meses de junho $(1,6 \%)$ (marcado pelo feriado nacional de Corpus Christi, período escolhido para realização do evento "Motocycle", que reunia motociclistas de vários municípios do país) e dezembro (1,4\%). Nos meses de setembro e dezembro, outra motivação também destacou-se nas respostas: as atividades profissionais. E, no mês de novembro, igualmente destacaram-se estudos e atividades profissionais (na opção "outras motivações").

Os resultados da pesquisa apontaram que a prática do lazer (na natureza, na praia, na cultura, no misticismo, nas águas termais ou simplesmente no ato de passear e conhecer a localidade) na Região Encontro das Águas foi compartilhada pelos respondentes na viagem junto à família, especialmente. Dentre os respondentes que apontaram o lazer como principal motivação para viajar até a Região Encontro das Águas (304 respondentes). 34,2\% mencionaram o "sol e praia" como principal atrativo; $32,6 \%$ apontaram outros motivos, dentre eles: as águas termais, o descanso, o passeio, conhecer a localidade, o Porto do Baé (complexo de lazer às margens do Rio Araguaia), os clubes, a vida noturna, a gastronomia e a contemplação. $27,0 \%$ apontaram a natureza, o ecoturismo e a aventura como principais atrativos para o lazer.

O tempo médio de permanência do turista na Região Encontro das Águas foi de 4,9 dias. Verificou-se que a maior distância dos municípios emissores com o destino não foi fator determinante para a maior permanência. Por exemplo, turistas do Estado de São Paulo ficaram em média, 7,8 dias, enquanto que os de outros estados (Alagoas, Maranhão, Bahia, Espírito Santo, Rio Grande do Sul, Mato Grosso do Sul, Santa 
Catarina, Pará, Pernambuco, Paraná, Rio de Janeiro) permaneceram no destino por cerca de 4,9 dias e os de outros países, 11,3 dias.

Por outro lado, distintas motivações foram fatores que influenciaram diretamente na permanência do turista. Primeiramente, a busca por serviços de saúde provocou o deslocamento de 5,78\% do total de respondentes e a permanência média de 7,5 dias; visita a amigos e parentes implicou, em média, a 5,3 dias de permanência, seguida de negócios, com média de 5,2 dias. As atividades profissionais implicaram na permanência média de 3,5 dias.

Segundo a Secretaria de Atenção à Saúde (BRASIL, 2013b), Barra do Garças, Pontal do Araguaia e Aragarças contavam respectivamente com: 112, 7 e 13 estabelecimentos de saúde. Quanto aos leitos hospitalares, Barra do Garças possuía 107 e Aragarças, 40. Em Pontal do Araguaia, constatou-se não haver registro de leitos hospitalares. A diversidade de especialistas da área da saúde, a disponibilidade de leitos hospitalares e a capacidade de realização de cirurgias, entre outros, garantiram melhor suporte aos pacientes e familiares nos tratamentos de saúde de grande parte da região, em especial àqueles que não podiam se deslocar aos grandes centros. De acordo com a Secretaria de Estado de Saúde (MATO GROSSO, 2011), o município de Barra do Garças estava atendendo moradores de Araguaiana, Campinápolis, General Carneiro, Nova Xavantina, Novo São Joaquim, Pontal do Araguaia, Ponte Branca, Ribeirãozinho, Torixoréu e o próprio município; e, certamente de municípios do Estado de Goiás.

Da mesma forma, verificaram-se as motivações por estudo e por qualificação profissional (somando 3,9\% dos respondentes). A esse respeito, conferiu-se que, na Região Encontro das Águas, encontravam-se: o Campus Araguaia da Universidade Federal de Mato Grosso, que estava oferecendo 16 cursos de graduação, dois mestrados stricto sensu e um mestrado profissional (UNIVERSIDADE FEDERAL DE MATO GROSSO, 2013); a Faculdades Unidas do Vale do Araguaia (UNIVAR), com oferta de 14 cursos de graduação e sete cursos de especialização (FACULDADES UNIDAS DO VALE DO ARAGUAIA, 2013); a Universidade de Cuiabá (UNIC), que possuía dois cursos de graduação (UNIVERSIDADE DE CUIABÁ, 2013); a Faculdade Cathedral, que dispunha de oito cursos de graduação (FACULDADE CATHEDRAL DE ENSINO SUPERIOR, 2013); e o Instituto Federal Mato Grosso (IFMT), campus de Barra do 
Garças, com oferta de três cursos técnicos (INSTITUTO FEDERAL MATO GROSSO, 2013).

O tempo médio de permanência também foi influenciado pelo meio de hospedagem utilizado. $\mathrm{O}$ meio de hospedagem que registrou a menor permanência foi $\mathrm{O}$ camping. Este tipo de acomodação foi utilizado principalmente durante a Temporada de Praia nas praias e nas matas ciliares. Não havia espaço público permanente destinado ao camping na localidade, mas existiam áreas de camping privadas. $\mathrm{O}$ acampamento, tão característico do turismo da Temporada de Praia de Aruanã (GO) que se prolongava por semanas, não encontrou a mesma expressividade na Região Encontro das Águas. Na opção "Outros", apareceram as seguintes respostas: casa alugada, alojamento, propriedade rural e local de trabalho.

O tipo de hospedagem forneceu indicativos das relações de produção do turismo no locus da pesquisa, pois caracterizou diferentes maneiras de se apropriar do espaço e da experiência turística.

A preferência do turista pela Região Encontro das Águas recaiu sobre a hospedagem na casa de amigos e parentes com $61,4 \%$, o que comprovou que muitos turistas optaram pela hospitalidade doméstica quando viajavam, seguida pela preferência por hotéis/pousadas: $31,1 \%$.

Visitar amigos e parentes é uma das principais motivações para as viagens no Brasil (BRASIL, 2012a) e no mundo (WORLD TOURISM ORGANIZATION, 2012). Visiting Friends and Relatives (VFR) é objeto de estudo em vários países, tais como: Estados Unidos, França e Austrália, entretanto é negligenciado por outros os quais negam a importância desse grande grupo de turistas (BACKER, 2009). Contudo, no levantamento sobre o turismo doméstico realizado pela Fundação Instituto de Pesquisas Econômicas (FIPE), em 2010/2011, o meio de hospedagem casa de amigos e parentes teve participação relativa de 62,8\% dos turistas (BRASIL, 2012a). “[...] Turistas VFR não estão apenas visitando amigos e/ou parentes. Eles também podem usar serviços fornecidos pela indústria do turismo, embora até este ponto, é desconhecido e atraiu relativamente pouca pesquisa" (BACKER, 2008, p. 52, tradução livre). A autora citada ressalta, em seu estudo, que a visita a parentes e amigos está associada a outras motivações como conhecer os atrativos turísticos da destinação, além da significativa influência dos anfitriões na definição de passeios e lugares a serem visitados. 
As relações afetivas (familiares e de amizade) foram as principais motivações para o deslocamento até a localidade pesquisada (30,1\%), mas, segundo Backer (2008), tais tipos de motivações podem estar associadas aos atrativos turísticos locais. No caso da localidade em estudo, tais atrativos seriam: praias, bares e restaurantes, águas termais, cachoeiras, rios, mirantes entre outros. Aliás, os recursos hídricos foram os principais atrativos turísticos mencionados, referentes à Região Encontro das Águas - e reforçaram tal topônimo. Outro fator determinante da hospitalidade doméstica foi a grande participação dos anfitriões, pois influenciaram na escolha dos atrativos turísticos, superando as campanhas publicitárias. As pessoas que se deslocaram para visitar amigos e parentes na Região Encontro das Águas apontaram, principalmente, os seguintes atrativos: Parque Municipal das Águas Quentes, Porto do Baé e Mirante do Cristo.

A pesquisa de campo revelou que a indicação para realizar o turismo na Região Encontro das Águas passava por reduzida referência à mídia e considerável participação e indicação de amigos e parentes nas decisões da visitação. O turista foi predominantemente proveniente dos Estados de Goiás e Mato Grosso. O primeiro, o do Estado de Goiás, reproduzia, no Rio Araguaia e em seus afluentes, as práticas de lazer em um ritual anual consagrado no período de vazante do rio (abril a setembro), enquanto o do Estado de Mato Grosso vislumbrava mais o fortalecimento das relações interpessoais (visita a amigos e parentes).

\begin{abstract}
Um movimento de (re)construção de identidade, identificando o rio por momentos comuns do mesmo passado. Essa rememoração coletiva de uma experiência vivida ancestralmente impulsiona os goianos a buscar no passado uma tradição, que no caso, tem como sustentação o imaginário coletivo da natureza intocada, selvagem, o jardim do Éden, o Paraíso (ELIADE ${ }^{8}$ apud RAMOS, 2011, p. 125).
\end{abstract}

Ramos (2011), em sua tese, defende que os acampamentos às margens do Rio Araguaia, que perduram por mais de quatro décadas, sejam um ritual de apropriação das praias por goianos na prática dos banhos, da pesca e do consumo de bebida alcóolica. Anualmente, as demarcações dos acampamentos são feitas no início do período de vazante do rio e, frequentemente, comercializadas. (RAMOS, 2011)

\footnotetext{
${ }^{8}$ ELIADE, M. Imagens e símbolos: ensaio sobre o simbolismo mágico religioso. Trad. Sônia Cristina Tamer. São Paulo: Martins Fontes, 1991.
} 


\section{CONSIDERAÇÕES FINAIS}

A produção do espaço pelo turista é marcada por trajetórias que envolvem o próprio turista, os trabalhadores diretos e indiretos do mercado turístico, gestores públicos e a população local. Contudo, no estudo realizado, buscou-se destacar características e comportamentos do turista e da sua viagem que evidenciassem a sua espacialidade na Região Encontro das Águas, a começar pela constatação de ocorrência de um turismo regional com deslocamentos em um raio de até 511 quilômetros, predominantemente.

A aplicação de 95 formulários mensais ao longo de 12 meses na Região Encontro das Águas (Barra do Garças - MT, Pontal do Araguaia - MT e Aragarças GO) - ou seja, 1.140 turistas respondentes no período de abril de 2012 a março de 2013 - foi a técnica de coleta de dados empregada para atingir os objetivos da pesquisa. $\mathrm{O}$ turista da Região Encontro das Águas foi proveniente, principalmente, da Região Centro-Oeste (com predomínio dos Estados de Mato Grosso e Goiás - estes dois somaram $87,5 \%$ dos respondentes) e suas motivações são diferenciadas ao longo do ano.

Tal pesquisa revelou novas nuances do turismo e da espacialidade do turista, especialmente, em se tratando de comportamentos culturais regionais e do predomínio do turismo de visita a amigos e parentes (30,1\% dos respondentes). A hospitalidade doméstica (hospedagem em casa de amigos e parentes) e a viagem VFR (Visiting Friends and Relatives) mostraram-se significativas nas práticas do turismo da Região Encontro das Águas. A pesquisa de campo apontou que 26,7\% dos turistas se deslocaram à Região Encontro das Águas para a prática de lazer; 19,1\% motivados por negócios; 7,3\% para participação em eventos e 16,8\% por várias outras razões (estudos, motivos profissionais, saúde, repouso, providenciar documentação, finanças, religião, compras, acompanhar amigo, concurso, entre outras). Na Região Encontro das Águas, identificou-se um turismo com predominância da hospitalidade doméstica, em que o turista ficou mais próximo da população local.

Ressalta-se que a "natureza" se configurou como principal atrativo turístico da Região Encontro das Águas, materializando-se nos rios, nas praias, nas cachoeiras, no Parque das Águas Quentes e em “pesque-pagues”. Contudo, a espacialidade do turista 
também esteve intrinsecamente relacionada a vários outros aspectos: educação, saúde, lazer, trabalho dentre outros.

\section{REFERÊNCIAS}

AQUINO, S.; LATRUBESSE, E. M.; SOUZA FILHO, E. E. Relações entre o regime hidrológico e os ecossistemas aquáticos da planície aluvial do rio Araguaia. Acta Scientiarum. Biological Sciences, Maringá, v. 30, n. 4, p. 361-369, 2008.

BACKER, E. R. VFR travellers - visiting the destination or visiting the hosts? Asian Journal of Tourism and Hospitality Research, Quezon City, v. 2, n. 1, p. 60-70, 2008.

VFR travel: an assessment of VFR versus non-VFR travellers. Lismore, 2009. $256 \mathrm{f}$. Tese (Doutorado em Filosofia) - School of Tourism and Hospitality Management, Southern Cross University, 2009.

BARRA DO GARÇAS. Conselho Municipal de Turismo. Lei no 2.357 de 15 de outubro de 2001. Dispõe sobre a criação do COMTUR. Barra do Garças, 15 out. 2001.

BENI, M. C. Análise estrutural do turismo. 4. ed. São Paulo: Senac São Paulo, 2001.

BONELLI, R. B. Turismo rodoviário: caracterização dos fretamentos a partir do Município de Bauru - SP. Rosana, 2009. 80 f. Monografia (Graduação em Turismo) Universidade Estadual Paulista "Júlio de Mesquita Filho", 2009.

BORGES, D. R. Rio Araguaia, corpo e alma. São Paulo: IBRASA, Universidade de São Paulo, 1987.

BRASIL. Estatuto da Criança e do Adolescente. Lei no 8.069/90 de 13 de junho de 1990. Dispõe sobre o Estatuto da Criança e do Adolescente e dá outras providências. Brasília, 13 jul. 1990.

Ministério da Saúde. Rede integrada de informações para a saúde. Indicadores socioeconômicos. IDB 2011 Brasil. 2011. Disponível em: <http://tabnet.datasus.gov.br/cgi/tabcgi.exe?idb2011/b08a.def $>$. Acesso em: 24/03/2014.

Ministério do Turismo. Caracterização e dimensionamento do turismo doméstico no Brasil - 2010/2011. Relatório executivo - produto 6. 2012a. Disponível em: <www.dadosefatos.turismo.gov.br>. Acesso em: 08/04/2013. 
Ministério do Turismo. Anuário Estatístico de Turismo - 2012. Ano base 2011. v. 39, 2012b. Disponível em: <http://www.dadosefatos.turismo.gov.br>. Acesso em: $17 / 09 / 2012$.

Ministério do Turismo. Glossário de turismo. 2013a. Disponível em: <http://www.dadosefatos.turismo.gov.br>. Acesso em: 25/03/2013.

Ministério da Saúde. Secretaria de Atenção à Saúde. Cadastro Nacional de Estabelecimentos de Saúde. 2013b. Disponível em: <http://cnes.datasus.gov.br/>. Acesso em: 02/08/2013.

DELAURIERS, J.; KÉRISIT, M. O delineamento de pesquisa qualitativa. In: DESLAURIERS, J.; POUPART, J.; GROULX, L.; LAPERRIÈRE, A.; MAYER, R.; PIRES, A. P. A pesquisa qualitativa: enfoques epistemológicos e metodológicos. 2. ed. Petrópolis: Vozes, 2010. p. 127-153.

DENCKER, A. de F. M. Pesquisa em turismo: planejamento, métodos e técnicas. 9. ed. São Paulo: Futura, 1998.

FACULDADE CATHEDRAL DE ENSINO SUPERIOR. Graduação. 2013. Disponível em: <http://www.faculdadecathedral.edu.br/portal>. Acesso em: 28/09/2013.

FACULDADES UNIDAS DO VALE DO ARAGUAIA. Cursos. 2013. Disponível em: $<$ http://univar.edu.br/>. Acesso em: 28/09/2013.

GARCIA, R. M. de P. Espacialidade e turismo: estudos exploratórios. In: ENCONTRO NACIONAL DE GEÓGRAFOS, 17, 2012, Belo Horizonte. Anais... Belo Horizonte: AGB, 2012, p. 1-12.

A produção do espaço pelo turista na Região Encontro das Águas: geossímbolos do Araguaia. Niterói, 2014. 185 f. Tese (Doutorado em Geografia) Instituto de Geociências, Universidade Federal Fluminense, 2014.

HAESBAERT, R. O mito da desterritorialização: do "fim dos territórios" à multiterritorialidade. 5. ed. Rio de Janeiro: Bertrand Brasil, 2010.

IBGE. INSTITUTO BRASILEIRO DE GEOGRAFIA E ESTATÍSTICA. IBGE cidades 2013. 2013. Disponível em: <http://cidades.ibge.gov.br>. Acesso em: 21/01/2014.

INSTITUTO FEDERAL MATO GROSSO. Campus Barra do Garças. Ensino. 2013. Disponível em: <http://bag.ifmt.edu.br/>. Acesso em: 28/09/2013.

MARIMON, B. S.; MARIMON JÚNIOR, B. H.; LIMA, H. S.; JANCOSKI, H. S.; FRANCZAK, D. D.; MEWS, H. A.; MARESCO, M. C. Pantanal do Araguaia ambiente e povo: guia de ecoturismo. Cáceres: UNEMAT, 2008. 
MATO GROSSO. Secretaria de Estado de Saúde. Informações regionais de saúde ERS de Barra do Garças - MT, 2010. Cuiabá: Secretaria de Estado de Saúde, 2011.

- Secretaria de Estado de Desenvolvimento do Turismo. Plano de desenvolvimento integrado do turismo sustentável - PDITS do Polo Araguaia Matogrossense. Cuiabá: SEDTUR; Rio de Janeiro: FGV; Brasília: Ministério do Turismo, 2013.

MOTTA, R. S.; ORTIZ, R. A.; FERRAZ, C. Estimando o valor ambiental do Parque Nacional do Iguaçu: uma aplicação do método de custo de viagem. Rio de Janeiro, IPEA, 2001.

NASCIMENTO, A. M. O espaço e contexto histórico de Barra do Garças: conhecendo as histórias de ocupação do lugar. Interdisciplinar: Revista Eletrônica da Univar, Barra do Garças, v. 2, n. 6, p. 256-261, 2011.

NASCIMENTO, A. M. V.; ROCHA, L. K. S.; AZEVEDO, F. F. de; MORAIS, I. R. D. Turismo e transformações socioespaciais: uma aproximação teórica e conceitual. Turismo \& Sociedade, Curitiba, v. 6, n. 2, p. 388-407, 2013.

OMT. ORGANIZAÇÃO MUNDIAL DO TURISMO. Introdução ao turismo. São Paulo: Roca, 2001.

PEARCE, D. G. Geografia do turismo: fluxos e regiões no mercado e viagens. São Paulo: Aleph, 2003.

PIRES, Á. P. Amostragem e pesquisa qualitativa: ensaio teórico e metodológico. In: DESLAURIERS, J.; POUPART, J.; GROULX, L.; LAPERRIÈRE, A.; MAYER, R.; PIRES, A. P. A pesquisa qualitativa: enfoques epistemológicos e metodológicos. 2. ed. Petrópolis: Vozes, 2010. p. 154-211.

RAMOS, L. M. J. Romaria das águas: ambiente, afeto e representações nas praias do Rio Araguaia/GO. Goiânia, 2011. 241 f. Tese (Doutorado em Geografia) - Instituto de Estudos Socioambientais, Universidade Federal de Goiás, Goiânia, 2011.

TAGLIACARNE, G. Pesquisa de mercado. São Paulo: Atlas, 1976.

UNIVERSIDADE DE CUIABÁ. Cursos. 2013. Disponível em: <http://faculdadesja.com.br/faculdades/universidade-de-cuiaba-unic >. Acesso em: 28/09/2013.

UNIVERSIDADE DO ESTADO DE MATO GROSSO. Laboratório de Análise Ambiental. Mapa: Região Encontro das Águas. Nova Xavantina: UNEMAT, 2013a.

Laboratório de Análise Ambiental. Mapa: Pontos de coleta de dados. Nova Xavantina: UNEMAT, 2013b. 
UNIVERSIDADE FEDERAL DE MATO GROSSO. Campus Universitário do Alto Araguaia. 2013. Disponível em: <http://araguaia.ufmt.br/>. Acesso em: 28/09/2013.

VIAGEM E TURISMO. Mapas e rotas. 2016. Disponível em: <http://viajeaqui.abril.com.br/>. Acesso em: 15/06/2016.

WADA, E. K. Turismo de negócios: viagens corporativas, eventos e incentivos. In: PANOSSO NETTO, A.; ANSARAH, M. G. R. (Ed.). Segmentação do mercado turístico: estudos, produtos e perspectivas. Barueri: Manole, 2009. p. 213-239.

WORLD TOURISM ORGANIZATION. Annual report 2011. Madrid: UNWTO, 2012. Disponível em: <http://www2.unwto.org/en/publication/unwto-annual-report2011>. Acesso em: 09/04/2013.

Recebido em: 24-03-2015.

Aprovado em: 23-04-2015. 